\title{
AN EMPIRICAL ANALYSIS OF THE RELATIONSHIP BETWEEN THE INFORMATION QUALITY OF CSR REPORTING AND REPUTATION AMONG PUBLICLY-TRADED COMPANIES IN SPAIN
}

\begin{abstract}
Purpose - Supported by the principles of the legitimacy theory, the authors of this paper explore the relationship that exists between the information quality of the Corporate Social Responsibility (CSR) reporting provided by the most liquid companies operating in the Spanish Stock Market and their corporate reputation.

Design/methodology/approach - Three regression models are tested with panel data collected for a sample of the 35 most liquid companies operating in the Spanish Stock Market between 2004 and 2014.

Findings - The findings show that two axes of information quality (i.e., Content and Management Systems) should be necessarily controlled by companies in order to improve their corporate reputation through their CSR reporting. The Content axis refers to the compliance of CSR reports with the provision of qualitative, quantitative and evaluative information concerning the impacts of the CSR of the company on the society and environment. The Management Systems axis refers to the compliance of CSR reports with the disclosure of details about the policies, plans and actions that companies implement to assure an effective management of CSR initiatives.

Originality/value - Previous literature exploring the relationship between corporate reporting and reputation has frequently focused on either (1) the impact of the quantity of financial and CSR information reported by companies and (2) the role of information quality, but only referred to some specific themes (environment, customers) and not to the full range of information covered by CSR reports. The authors of this paper extend on previous academic
\end{abstract}


literature by empirically evaluating the relationship between two dimensions of the information quality of CSR reporting (content and management systems) and the corporate reputation of companies operating in the Spanish Stock Market.

\section{KEYWORDS}

Corporate social responsibility; reporting; legitimacy; transparency; reputation

\section{ARTICLE CLASSIFICATION:}

Research paper

JEL CLASSIFICATION:

M14 Corporate Culture • Diversity • Social Responsibility

\section{MANAGEMENT AREA:}

Ethics and social responsibility 


\section{INTRODUCTION}

When the traditional foundations of business ethics fail, new corporate strategies should be requested from companies to demonstrate their ethical standards. For example, in their search for new paths to assist practitioners in enhancing the reputation of their companies, scholars have recently focused their attention on the benefits of corporate social responsibility (CSR) reporting. CSR reporting refers to the disclosure of the company activities demonstrating the inclusion of economic, social and environmental concerns in business actions and in interactions with stakeholders (Aguinis and Glavas, 2012). Specially based on institutional theories, such as the legitimacy theory (Patten, 1992), scholars have theoretically argued that transparent CSR reporting is part of the dialogue between an ethical company and its stakeholders that helps legitimizing corporate behavior and as so contributes to generating positive corporate reputation (Michelon, 2011). Based on this idea, there has been a fast growth in the number of CSR reports published in recent years. For example, more than $80 \%$ of the companies of the Fortune 500 address CSR reports on their websites (Lii and Lee, 2012).

Along this line, both information quantity and quality have been especially useful for scholars when determining the relevance of transparent CSR reporting to generate corporate reputation. For example, many scholars have discussed the positive effect of a large quantity of CSR reporting in corporate reputation (Unerman, 2008). Nonetheless, it follows from earlier theoretical discussion that the volume of reporting alone is not in itself sufficient condition for the creation of corporate reputation (Toms, 2002). Scholars have demonstrated that the reliance on a mere number of disclosures may be misleading and they have proposed that research can be taken further using a framework of information quality (Toms, 2002; de los Ríos et al., 2012). In this regard, previous literature suggests that quality signaling does not 
depend on the quantity of information provided by companies. Rather it is the relevance, comparability, verifiability, clarity and neutrality of the information that is important (Chauvey et al., 2014). Scholars have lately defended that information quality must have a more significant influence on corporate reputation than the mere reporting of large amounts of quantitative or qualitative information (Toms, 2002; de los Ríos et al., 2012).

However, and due to the novelty of the later line of research, the authors of the present paper have identified some gaps in previous literature that justify further study on the relationship between the information quality of CSR reporting and corporate reputation. First, it seems clear that financial information is the most relevant for companies as it is the first to become standardized and mandatory in many countries (Lightstone and Driscoll, 2008). However, research aiming to analyze the effect of the quality of the information related to non-financial and non-regulated features, grouped in voluntary CSR reporting, is less numerous, more heterogeneous and less conclusive (Willis, 2003). Second, this stream of research is mostly theoretical in nature (Bebbington et al., 2008) and scholars have still developed very few empirical papers to discuss the validity of the theoretical reasoning described above (Toms, 2002; de los Ríos et al., 2012). Finally, it is also noticeable that the few scholars who have empirically analyzed the effect of the information quality of CSR reporting on corporate reputation have only analyzed the information quality on very specific themes such as environmental management (Toms, 2002) or CSR information to customers (de los Ríos et al., 2012). However, nowadays the definition of CSR reporting that prevails among scholars and practitioners is much more comprehensive than these approaches and it also includes information to diverse stakeholders (e.g., investors, employees, local communities) on environmental but also economic and social issues. Thus, further empirical research is needed to fill the gaps identified in previous literature. 
Based on these ideas, in this paper the authors extend on the academic literature on CSR reporting and corporate reputation by empirically evaluating the relationship between two dimensions of information quality (content and management systems) and the corporate reputation of companies included in the Ibex35, which is the most relevant index of the Spain Stock Market. For this purpose, the authors base their reasoning on the legitimacy theory, which consistently support the relationship between institutional pressures, CSR reporting, transparency (information quantity and quality) and corporate reputation (Aguinis and Glavas, 2012; Fernández-Feijoo et al., 2014; Cormier and Magnan, 2015). Along this line, the paper contributions to literature are twofold. First, the authors provide further empirical evidence on a line of research relevant for companies but scarcely developed so far. Secondly, the authors evaluate the information quality of CSR reporting that includes a wide range of information on economic, social, environmental, human rights and corporate governance issues in order for the findings to be easier to generalize than previous research.

The remainder of the paper is structured as follows. In the second section of the paper, a theoretical overview of the legitimacy theory and the relevance of transparency, information quantity and quality is discussed and the research hypotheses are presented. Afterwards, the authors describe the method applied to the study. They also outline and discuss the results of the paper. Finally, the most relevant conclusions, limitations and future lines of research are summarized.

\section{BACKGROUND AND HYPOTHESES}

\subsection{An overview of legitimacy theory}

The concept of legitimacy, with its roots in institutional theories (Aguinis and Glavas, 2012), constitutes a prominent theoretical perspective in CSR reporting research (Cormier and 
Magnan, 2015). Legitimacy is defined as a generalized perception held by stakeholders that the actions of a company are desirable, proper, or appropriate within some socially constructed system of norms, values, beliefs, and definitions (Suchman, 1995). The legitimacy theory defends that legitimacy and beneficial stakeholder relationships are built through communication, which assists companies in managing favorable stakeholders' perceptions and guiding the future actions of stakeholders (King and Whetten, 2008). van Riel (2000) considers that communication enables a company to begin a dialogue to create awareness, understanding, and appreciating for its strategic goals, ideally resulting in the satisfaction of the interests of both the company and its stakeholders.

Under the light of the legitimacy theory, scholars have either tried to (1) gain a better understanding of companies' underlying motivation to provide CSR reporting (Brammer and Pavelin, 2008; Nikolaeva and Bicho, 2011; Aguinis and Glavas, 2012; Fernández-Feijoo et al., 2014) or (2) explain the positive impacts of such reporting for companies (Aerts and Cormier, 2009; Cormier and Magnan, 2015). Gray et al. (1996, p. 45) note that legitimacy is a 'systemsoriented' theory that underlines the explorations of the 'role of information and disclosure in the relationship between organizations, the State, individuals, and groups'. Deegan (2002, p. 292) further states that 'systems-oriented' theories recognize CSR reporting as an 'important means by which management can influence external perceptions about their organization'.

First, the legitimacy theory looks at CSR reporting as a legitimacy management tool that responds to institutional pressures by stakeholders (Nikolaeva and Bicho, 2011). Over several decades, scholars exploring CSR reporting from an institutional perspective have found that different stakeholders have different expectations regarding a company's CSR. These stakeholders take on different roles and engage in different activities while attempting to influence companies to engage in CSR (Aguinis and Glavas, 2012). According to Chauvey et al. 
(2014), 'where firms face exposures to the social and political processes (institutional pressures) through which social legitimacy is monitored and bestowed (Patten, 1992), they have an incentive to use disclosure to enhance their legitimacy. As such, differences in social and political exposures are expected to be associated with differences in CSR disclosure'. Along this line, Coebergh (2011) defends that companies need to engage with stakeholders as they have the power to influence the achievement of organizational outcomes. Thus, establishing good relationships with stakeholders through CSR reporting can be seen as an intangible organizational source of competitive advantage (Coebergh, 2011).

Second, a consistent finding regarding the outcomes of CSR reporting from a legitimacy perspective is an improvement in a company's reputation (Aguinis and Glavas, 2012). Scholars consider that legitimacy is a 'process that translates past performance into an expectation for the future' (de Quevedo et al., 2007, p. 60). Thus, legitimacy transforms CSR reporting, an objective flow variable, into corporate reputation, a perceptual stock variable (de Quevedo et al., 2007). Along this line, King and Whetten (2008) believe that the link that provides common ground for the treatment of legitimacy and reputation as complementary concepts is the notion of corporate identity, which is commonly reflected in the CSR reports where companies express their own culture, values and personality (Nikolaeva and Bicho, 2011). As explained by Nikolaeva and Bicho (2011, p. 143), companies 'have various 'communicators of identity', which can be used to build reputation and over which they exercise different degrees of control (Bhattacharya and Sen, 2003)'. Among the communicators identified by these scholars, the most controllable ones are corporate communications that are used as public relations (PR). Carter (2006) refers to PR actions, such as CSR reporting, as reputation management activities whose goal is to shape a company's reputation in the eyes of its stakeholders. Specifically, a company's CSR reporting influences how its stakeholders 
perceive its legitimacy in such a way that enhanced legitimacy reduces the information uncertainty faced by external stakeholders and it brings economic benefits in terms of social and political reputations (Pfarrer et al., 2010; Cormier and Magnan, 2015).

\subsection{Transparency in CSR reporting: Information quantity and quality}

A key concept in the legitimacy process suggested by institutional theories is transparency.

On the one hand, the transparency of CSR reporting is a frequent consequence of the institutional pressures exerted by several stakeholders of the company, such as customers, employees or the environment (Fernández-Feijoo et al., 2014). Dubbink et al. (2008) believe that some external pressure certainly can stimulate the internalization of virtues such as honesty, openness and integrity, which derive in companies willing to be more transparent in their CSR reporting. On the other hand, transparency improves corporate reputation (Dubbink et al., 2008). Specifically, the transparency of CSR reporting enhances the quality of stakeholders' information context, which ultimately allows them to make better forecasts and take better decisions. When stakeholders perceive this situation, it lead to the improvement of corporate legitimacy (Aerts and Cormier, 2009), which ultimately brings economic benefits to the company in terms of improved corporate reputation (Pfarrer et al., 2010).

As far as the definition of transparency is concerned, the literature reviewed shows the inexistence of a unique way to define and measure this concept. For example, several scholars suggest that the first requirement to achieve the transparency of CSR reporting relates to the disclosure of larger amounts of CSR information (Chauvey et al., 2014). Specifically, scholars frequently quantify transparency using space measures and content scores by counting the number of words, sentences or pages that companies devote to CSR in their financial or CSRspecific reports (Patten, 1992). Additionally, some scholars are also 'content or meaning oriented' (Chauvey et al., 2014) in the sense that they focus primarily on the number of 
underlying themes that are textually present in CSR reporting (Smith and Taffler, 2000). While space is not the same thing as quality, greater space allocation does imply increased information provision (Chauvey et al., 2014) and larger amounts of information represent a greater knowledge of the company by stakeholders, especially when compared to companies that do not report CSR information at all (Dubbink et al., 2008).

Nevertheless, while both the amount ('how much') and the themes ('what') of CSR reporting are potentially important for managers and report users, neither is a perfect measure of the transparency of information that is being provided (Chauvey et al., 2014). A new line of research argues that higher levels of transparency are associated with more confidence of stakeholders on the company's commitment to CSR (Fernández-Feijoo et al., 2014). This confidence is achieved through the improvement of the quality of the information included in CSR reporting rather than increased level of reporting (Chauvey et al., 2014). Quality should reside in the manner in which the reported information transforms stakeholders' knowledge of the company's corporate strategy, and CSR impact in particular (Brammer and Pavelin, 2008). Along this line of research, scholars have defended that information quality relates to whether the CSR reporting contains monetary, quantitative, or qualitative items or whether the CSR reporting is descriptive, vague or immaterial (Hughes et al., 2001). Overall, scholars frequently defend five major quality characteristics for CSR information: relevance, comparability, verifiability, clarity and neutrality (Chauvey et al., 2014).

The Figure 1 represents the conceptual framework for CSR reporting proposed by the legitimacy theory. It also summarizes some of the most significant papers that have empirically corroborated the relationships among institutional pressures, information quantity, information quality and corporate reputation under the light of the legitimacy 
theory. As it can be observed in the figure, while the research exploring other relationships in the framework has been extensive, there is still a scarce of empirical literature on the link between the quality of CSR reporting and corporate reputation. Covering this gap in previous literature is the main goal of this paper.

\section{Insert Figure 1 about here}

\subsection{Information quality and corporate reputation}

In order to improve the quality and transparency of CSR reporting, scholars have frequently defended the voluntary compliance of CSR reporting to internationally accepted CSR standards (Brammer and Pavelin, 2008; Fernández-Feijoo et al., 2014; Chauvey et al., 2014). These standards aim to develop a voluntary reporting framework that elevates CSR reporting practices to a level equivalent to that of financial reporting in rigor, comparability, auditability and general acceptance. Thus, CSR standards are emerging as important instruments to organize the discourse in CSR reports and show the company's commitment to stakeholders more clearly (Chauvey et al., 2014).

Among all the internationally accepted CSR standards, GRI is the most reputed and applied by companies (Nikolaeva and Bicho, 2011). The GRI is a 'non-profit organization that promotes economic, environmental, and social sustainability. GRI provides all companies and organizations with a comprehensive sustainability reporting framework that is widely used around the world' (GRI, 2014). The guidelines proposed by the GRI specify the reporting of qualitative and quantitative economic, social and environmental information that must be reported in a relevant, comparable, verifiable, clear and neutral way in order for the company to achieve an A (maximum qualification) in the evaluation of CSR reporting provided by the GRI (Brammer and Pavelin, 2008). More specifically, the GRI guidelines for CSR reporting are divided into two areas: (1) the GRI indicators and (2) the Disclosures on Management 
Approach (DMA) (GRI, 2014). On the one hand, the GRI indicators allow companies to provide comparable information on their economic, social and environmental performance. On the other hand, the DMA provide the company with an opportunity to explain how it is managing its material economic, environmental or social impacts (aspects). The DMA focus on three things: describing why an aspect is material, how its impacts are being managed, and how the approach to managing this aspect is being evaluated.

This structure of CSR standards provided by the GRI is in line with the theoretical approaches developed in academic literature so far. Along this line, scholars have determined that companies that care about their legitimacy and reputation must also care about (1) how stakeholders assess their satisfaction with the distribution of the value created by the company, and (2) how corporate governance structures and policies are perceived by the stakeholder community that monitors their activities (de la Fuente and de Quevedo, 2003). Thus, high quality CSR information includes relevant, comparable, verifiable, clear and neutral information (Chauvey et al., 2014) on (1) the economic, social and environmental value generated by the CSR initiatives promoted by the company (i.e., the content of CSR reporting) and (2) the management systems implemented to manage CSR (CSR Observatory, 2013).

As for the relationship between the information quality of CSR reporting and corporate reputation, some interesting insights can be obtained from the previous literature that has focused on explaining why CSR standards become institutionalized both within and across industries (Bebbington et al., 2008). For example, Bebbington et al. (2008) developed a model to explain the diffusion of CSR standards, a process that results in slowly ratcheting expectations over time. More specifically, when companies adopt CSR standards in their CSR reporting, they increase their stakeholders' expectations and, when they are able to satisfy these expectations, their reputation increases. This creates a cycle whereby the general 
diffusion of these standards improves the quality of CSR reporting and it creates a new expectation gap for most companies. Their subsequent response will launch another cycle and, over time, raise expectations for CSR for all companies improve the quality of CSR reporting and their reputation significantly. In contrast, failures to adhere to the CSR guidelines of performance and behavior recommended by these standards are likely (especially if uncovered) to give rise to serious legitimacy threats that strongly penalize reputation (Bebbington et al., 2008). Bebbington et al. (2008) highlight Enron's demise as one of the most recent and high profile examples of the relationship between CSR standards, transparency and reputation management.

For the purposes of this research, it is also important to highlight that previous empirical papers have already tested and confirmed how the information quality of some areas of CSR reporting is especially relevant to explain corporate reputation. For example, Toms (2002) finds that the information quality on environmental issues is positively correlated with better corporate reputation. De los Ríos et al. (2012) also find that the quality of the information provided to customers positively and significantly determines corporate reputation in the Spanish context. Nonetheless, these papers do not provide a comprehensive understanding of the role that the information quality of the CSR reporting that includes a broader scope of CSR initiatives can have on corporate reputation. By evaluating the content and management systems disclosed in CSR reporting according to the GRI guidelines, the measurement of information quality used in the present paper covers this gap in literature because it evaluates the information quality of CSR reporting on multiple issues such as social and environmental management, human rights and corporate governance (CSR Observatory, 2013; GRI, 2014). Based on these ideas, the authors propose to test the following research hypotheses: 
$\mathrm{H1}$ : There is a positive relationship between the information quality of CSR reporting and corporate reputation. Specifically,

H1a: There is a positive relationship between the information quality of the content reported in CSR reports and corporate reputation.

$\mathrm{H1b}$ : There is a positive relationship between the information quality of the management systems reported in CSR reports and corporate reputation.

\section{METHODOLOGY}

\subsection{Sample}

The sample in the study is compounded of all the companies that have been historically included (between 2004 and 2014) in the report "CSR in the annual reports of the Ibex35 companies" that the Spanish Observatory for Corporate Social Responsibility (CSR Observatory) provides annually to assess the information quality of the CSR reporting of Spanish listed companies. The CSR Observatory (http://observatoriorse.org/) is a nonprofit organization founded in 2004 with the aim of working in promoting the correct application of the CSR principles in Spain. Since its inception, the CSR Observatory functions as a wellreputed platform for cooperation and research to promote CSR in business, advocate private practices and monitor public policies and their practical applications.

The companies rated by the CSR Observatory are listed companies of the Spanish Stock Market included in the Ibex35 index, which is made up by the 35 most liquid securities traded in the stock market. Nevertheless, and in order to perform valid analyses, two filters were applied in the selection of the sample:

1) First, the Ibex35 index composition is revised every year, with companies entering and/or leaving the index as a consequence of those revisions. Thus, the companies 
included in the index have not been the same during the whole period of analysis and more than 35 companies have had to be considered in the initial sample.

2) Nevertheless, some of the companies have had to be dropped from the sample because they do not regularly publish CSR reports and as so the information quality of their CSR reporting cannot be assessed.

After applying these filters, the composition of the sample is an unbalanced panel with 35 companies and 274 observations. Table 1 contains the industry distribution of the companies and observations in the sample.

\section{Insert Table 1 about here}

\subsection{Method}

To test the hypotheses, a multivariate analysis is performed. Specifically, the authors use the panel data methodology to test the three research hypotheses of the paper through three different statistical models. This method allows controlling for unobservable heterogeneity. Unobservable heterogeneity refers to the differences that exist between companies that give rise to several characteristics that influence their reputation but that are not observable or measurable (i.e., they cannot be introduced into the statistical analyses). The use of panel data allows controlling for this heterogeneity by taking the initial differences and thereby eliminating the individual effect $\left(\eta_{\mathrm{i}}\right)$, which allows avoiding significant bias in the findings.

The first model tested in the paper (Model 1 ) is designed to respond to the hypothesis $\mathrm{H} 1$ according to the following equation:

$$
\begin{aligned}
\operatorname{REPUT}_{i t}=\beta_{0} & +\beta_{1} \operatorname{IQCSRR}_{i t-1}+\beta_{2} \operatorname{SIZE}_{i t}+\beta_{3} \text { ROE }_{i t}+\beta_{4} A G E_{i t}+\sum_{j=1}^{3} \gamma_{j} \text { SECTOR }_{j i t} \\
& +\sum_{k=1}^{11} \phi_{k} Y_{\text {YEAR }}+\eta_{i}+\varepsilon_{i t}
\end{aligned}
$$


where,

IQCSRR $=$ the global information quality of the CSR reporting

SIZE $=$ total assets of the company

$\mathrm{ROE}=$ return on equity (financial performance)

$\mathrm{AGE}=$ years since establishment

SECTOR = industry in which the company operates

YEAR = year of the observation

In addition to this initial test of the hypothesis $\mathrm{H} 1$, the hypotheses $1 \mathrm{a}$ and $1 \mathrm{~b}$ are tested with two alternative specifications of the Model (1): Model (1a) and Model (1b). In these new specifications the authors include the assessment of the two axes of information quality provided by the CSR Observatory (i.e., Content (CONT) in Model (1a) and Management Systems (MANASYS) in Model (1b)) instead of the global assessment of information quality (IQCSRR) explored in the first Model (1). The new models follow these specifications:

$$
\begin{aligned}
& \operatorname{REPUT}_{i t}=\beta_{0}+\beta_{1} \operatorname{CONT}_{i t-1}+\beta_{2} \operatorname{SIZE}_{i t}+\beta_{3} \text { ROE }_{i t}+\beta_{4} A G E_{i t}+\sum_{j=1}^{3} \gamma_{j} \operatorname{SECTOR}_{j i t} \\
& +\sum_{k=1}^{11} \phi_{k} Y E A R_{k i t}+\eta_{i}+\varepsilon_{i t} \\
& \operatorname{REPUT}_{i t}=\beta_{0}+\beta_{1} \text { MANASYS }_{i t-1}+\beta_{2} \operatorname{SIZE}_{i t}+\beta_{3} \text { ROE }_{i t}+\beta_{4} A G E_{i t}+\sum_{j=1}^{3} \gamma_{j} \operatorname{SECTOR}_{j i t} \\
& +\sum_{k=1}^{11} \phi_{k} Y E A R_{k i t}+\eta_{i}+\varepsilon_{i t}
\end{aligned}
$$

where,

CONT = the information quality of the CSR reporting on the 'content' axis MANASYS = the information quality of the CSR reporting on the 'management systems' axis

SIZE $=$ total assets of the company

ROE = return on equity (financial performance)

$A G E=$ years since establishment

SECTOR = industry in which the company operates

YEAR = year of the observation 


\subsection{Variable definition}

\subsubsection{Dependent variable - Reputation}

The corporate reputation of the company (REPUT) is measured as the natural logarithm of the reputation of the company rated by the MercoEmpresas index annually. The introduction of this variable using the natural logarithm reduces the original dispersion of the data, making estimates less sensitive to extreme values. In addition, the risk of heteroscedasticity in the model is reduced by introducing the variable as a logarithm.

The MercoEmpresas index is a ranking of the top 100 companies with the highest reputation in Spain, which is elaborated annually by the Spanish Corporate Reputation Monitor (Merco). This indicator evaluates the opinions of different stakeholders, who select and evaluate companies through a postal survey. The survey evaluates companies on 17 items related to (1) financial results; (2) product/service quality; (3) management; (4) ethics and corporate social responsibility; (5) internal reputation and (6) digital communication (Table 2). This tool is already a reference for large companies in the assessment and management of their reputation, as it is the only Spanish monitor to evaluate annually (since 2001) the reputation of the companies that operate in Spain in a systematic and rigorous way (Luna and Fernández, 2010).

\section{Insert Table 2 about here}

The ranking is built in four stages. Firstly, the survey is administered to the members of the Steering Committees of companies operating in Spain with revenues exceeding $€ 50$ million ${ }^{1}$. These individuals are asked to spontaneously think of the ten companies and ten managers with the best reputation in Spain. Their assessment has a weight of 33\% in the final ranking.

\footnotetext{
${ }^{1}$ For example, in 2014 Merco collected a total of 1,260 valid surveys from members of Steering Committees.
} 
At this stage, about 800 companies are mentioned and the score of each company is a consequence of the number of mentions it receives and the place in which it has been referenced by the managers. This stage provisionally proposes the 100 most reputable companies in Spain.

Secondly, each of these 100 companies is evaluated by several expert raters: financial analysts, non-governmental organizations (NGOs), unions, consumer associations, journalists and other opinion leaders ${ }^{2}$. Each expert rates each company with a punctuation between 0 and 100 points in the variables that are assigned to him/her by Merco (see Table 2). The score of a company among each group of experts is the mean score that it obtains in the variables evaluated. The final scores are added (each based on its own weight) to the scores suggested by the members of the Steering Committees. This assessment has a weight of $32 \%$ in the final ranking.

Thirdly, Merco integrates the score of each company on two additional monitors (i.e., Merco Personas and Merco Consumo), which represents $20 \%$ of the final score of the companies in the ranking.

Finally, all these ratings are verified through research into the companies' own reports and through a "merit questionnaire" created by Merco analysts. This assessment represents $15 \%$ in the final ranking.

Once this four-stage process is completed, the definitive ranking is drawn up and released. The results of the MercoEmpresas reputation index are published each year by Cinco Días, one of the most renowned business journals in Spain, and they are also publicly available on the Merco website(www.merco.info/es).

\footnotetext{
${ }^{2}$ For example, in 2014 Merco collected a total of 949 valid surveys from these expert raters: 160 financial analysts, 132 NGO representatives, 111 union members, 111 consumer associations, 100 journalists and other 335 opinion leaders.
} 


\subsubsection{Independent variables - Information quality: Content and Management Systems}

In this paper, the main independent variable that is considered to explain reputation is the annual measure that the CSR Observatory provides to assess the information quality of the CSR reporting of the companies in the Ibex35 index (IQCSRR). Additionally, reputation is also related to other two variables that represent the main axes of information quality as measured by the CSR Observatory: the quality of the content of the CSR reporting (CONT) and the quality of the CSR management systems described by companies in their CSR reporting (MANASYS).

In the report "CSR in the annual reports of the Ibex35 companies", the CSR Observatory explains the procedure that it implements to evaluate the information quality of the CSR reporting. Specifically, each year the CSR Observatory implements a qualitative and quantitative analysis of the annual CSR and financial reports of the companies included in the Ibex35 index. The documents of each company are studied by several analysts of the CSR Observatory, who evaluate the information contained therein through 60 items classified according to the CONT and MANASYS variables (Table 3).

On the one hand, the variable CONT reflects the compliance of corporate reports with providing high quality information on the economic, social and environmental impacts of the CSR initiatives of companies according to the GRI Guidelines and the United Nations (UN) Human Rights Norms for Transnational Corporations (CSR Observatory, 2013). On the other hand, the variable MANASYS evaluates the compliance of corporate reports with the Accountability AA1000 Principles and Standards, the New Economics Foundation (NEF) Model and the GRI Principles and Profile section (CSR Observatory, 2013). Reporting CSR information according to these standards guarantees that stakeholders are properly informed about the 
mechanisms that the company implements to manage its CSR responsibilities (CSR Observatory, 2013).

\section{Insert Table 3 about here}

For each item, the following issues are analyzed: (1) the description of documentary evidence, (2) the number of pages of each report in which the information is described, (3) the numerical value of the item and (4) the conclusions derived from the item. Each item is scored on a scale of $0-4$ ( $0=$ nonexistent quality; $0.1-1=$ anecdotal quality; $1.01-2=$ poor quality; $2.01-3$ = incomplete quality; 3.01-3.99 = complete quality; 4 = comprehensive quality). CONT and MANASYS scores are calculated per company and then aggregated to show the mean values of these variables for the whole set of companies in the sample. Additionally, the CSR Observatory calculates the IQCSRR of each company as the arithmetic mean of the punctuation that it gets in the CONT and MANASYS variables. Afterwards, the information is also aggregated to show the mean IQCSRR value for the whole sample.

It is also important to highlight that for the purposes of the present study the IQCSRR, CONT and MANASYS variables are lagged one period. In this regard, corporate reputation is expected to depend on previous evidence and corporate activities that are always included in the CSR reporting of the last financial year. For example, the first edition of the MercoEmpresas reputation index was published on March 2004. By that time, the CSR and financial reports that had been published by companies in the lbex35 only referred to the previous financial year (2003), while all the CSR information concerning 2004 was not published until the year was over (i.e., the first semester of 2005).

\subsubsection{Control variables}

In order to avoid biased findings, control variables are also included in the research models. First, the authors control for corporate size (SIZE), measured as the natural logarithm of the 
total assets of the company (Hillman and Keim, 2001). The second control variable is financial performance, measured by the return on equity (ROE) (Fombrun and Shanley, 1990). The third control variable is company age (AGE), represented by the natural logarithm of the number of years since the establishment of the company. Three dummy variables ("basic industries", "consumer goods and services" and "finance") are included to control the company's industry. Lastly, year dummies are also included to capture year-specific effects.

\section{FINDINGS}

\subsection{Univariate findings}

Before testing the research hypotheses of the paper, the authors briefly describe several univariate findings concerning the information quality of the CSR reporting of the companies in the sample.

Figure 2 shows a summary of the information quality of CSR reporting for the period 20042013. The findings suggest that the information quality of CSR reporting remains low among the companies in the Ibex35. Specifically, in 2013 the assessment made by the CSR Observatory reflects a mean value of 1.35 in the IQCSRR variable, which is significantly below the maximum value of 4 that could be given to a company that scored the highest in each rated indicator.

Additionally, it is observed that the compliance with the standards evaluated by the CSR Observatory follows the same pattern year after year, with the Management Systems axis receiving the highest scores and the Content axis scoring significantly lower.

As far as the Content axis is concerned, the CSR Observatory reports that the companies in the Ibex35 index sometimes provide large amounts of quantitative, qualitative and evaluative information in their CSR reporting, especially concerning the outcomes of their CSR 
management. However, this information still lacks rigor, scope, sufficient quantity and quality (CSR Observatory, 2013). On the one hand, it seems that some companies still ignore the convenience of being accountable in terms of CSR concerns and they barely report significant CSR information. On the other hand, those companies that make more communication efforts do not always accompany that reporting with sufficient quantitative information concerning the impacts of their CSR management and the relevant events occurred in their companies year after year. They mostly report qualitative information (CSR Observatory, 2013). All in all, the average score in the Content axis for the companies in the sample is 1.31 , which is even lower than the average score for the IQCSRR variable.

Concerning the Management Systems axis, the CSR Observatory detects deficiencies regarding the consistency of information in such a way that while progress is evident in terms of the commitments, policies and plans implemented by the companies in the Ibex35 index, the information about their scope, effective implementation, monitoring and improvement is often insufficient and unclear (CSR Observatory, 2013). This information is very important because it is a clear demonstration of the commitment of companies to an effective CSR management that would differentiate their CSR reporting from a purely communicative and whitewashing approach. The findings show that, even though the scores are higher in this category than in the Content axis, still the mean is 1.53 , significantly below the maximum score available for companies.

\section{Insert Figure 2 about here}

\subsection{Multivariate findings}

As far as the findings of the research hypotheses are concerned, Tables 4 and 5 present the descriptive statistics and correlations among all the variables in the study. The findings show low correlations among most of the variables, which give no reason to suspect 
multicollinearity in the analyses (Fombrun and Shanley, 1990). However, there are high correlations among the three variables that assess the information quality of the CSR reporting of the companies in the Ibex35 index (Table 5). These findings reinforce the proposal of the authors to test the role of each information quality axis with an independent regression model.

\section{Insert Table 4 about here}

\section{Insert Table 5 about here}

Table 6 shows the results of the three regression analyses implemented to test the Models (1), (1a) and (1b). The estimation method is the fixed-effect model using the Huber/White/Sandwich estimator of the variance-covariance matrix. This estimation method allows controlling unspecified forms of heteroscedasticity. Thus, the findings calculated in this way are considered robust.

In order to check the suitability of this estimation method, different specification tests are presented in the Table 6. To check the convenience of using fixed-effects (or random effects) estimators, the Hausman's specification test is calculated under the null hypothesis that there should be no systematic difference between the fixed and random effects estimators. According to the results of this test, in the three models the hypothesis that a random-effect model adequately models the individual-level effects is rejected. Therefore, the three models are estimated using the fixed-effect model, which will capture all temporally constant individual-level effects. In addition to the Hausman's test, the F-test is also calculated under the null hypothesis that the individual fixed effects are equal to zero. In the three models, the F-test is statistically significant. Thus, the fixed effects are non-zero. This result suggests that 
applying a pooled OLS and a random effects method will be less adequate alternatives for this research than the fixed-effects method because they would bias the findings.

\section{Insert Table 6 about here}

According to the hypothesis $\mathrm{H} 1$, the coefficient $\beta_{1}$ should be positive in Model (1), reflecting that the companies with better information quality in their CSR reporting have greater corporate reputation. The findings show a statistically significant positive relationship between the global information quality of the CSR reporting of companies (IQCSRR) and their reputation (REPUT) (i.e., $\beta_{1}$ is positive and statistically different from zero). Based on these findings, the hypothesis $\mathrm{H} 1$ is supported.

When analyzing the influence of the two axes of IQCSRR over the company's reputation, the findings are also consistent with the hypotheses $\mathrm{H} 1 \mathrm{a}$ and $\mathrm{H} 1 \mathrm{~b}$. According to the hypothesis $\mathrm{H} 1 \mathrm{a}$, the coefficient $\beta_{1}$ should be positive in Model (1a), reflecting that the companies that show a better quality in the content of their CSR reporting have greater corporate reputation. The findings show a statistically significant positive relationship between the content of CSR reporting (CONT) and corporate reputation (REPUT) (i.e., $\beta_{1}$ is positive and statistically different from zero). Thus, the hypothesis $\mathrm{H} 1 \mathrm{a}$ is supported. According to the hypothesis $\mathrm{H} 1 \mathrm{~b}$, the coefficient $\beta_{1}$ should be positive in Model (1b), reflecting that the companies showing better quality in the information they provide about their CSR management systems have greater corporate reputation. The findings show a statistically significant positive relationship between the information about management systems in CSR reporting (MANASYS) and corporate reputation (REPUT) (i.e., $\beta_{1}$ is positive and statistically different from zero). Thus, the hypothesis $\mathrm{H} 1 \mathrm{~b}$ is also supported. 
Regarding the control variables, the findings show a positive and statistically significant effect of corporate size (SIZE) on corporate reputation (REPUT) in all the estimated models. This finding suggests that larger companies have a greater corporate reputation. On the contrary, the age (AGE) of the company has a statistically negative effect on corporate reputation (REPUT) in all the estimated models, meaning that older companies have poorer reputations than younger companies. Finally, financial performance (ROE) does not have any significant effect on the generation of corporate reputation (REPUT) in none of the three models.

For the industry and year effects, the Wald's test of the joint significance of the dummy variables is applied. In both cases, the joint effect is significant. Thus, the results are robust to the influence that both the industry and the temporary effect have on corporate reputation. In order to control the robustness of the findings, the Table 7 shows the results of the three regression analyses implemented to test the Models (1), (1a) and (1b) using the two-stage least-squares fixed-effects estimator with instrumental variables. This estimation method allows controlling the potential bias that could exist by the double causality relation between financial performance (ROE) and reputation. In particular, the method includes the first lag of the ROE as an instrument in each of the three regression analyses. The results of the analyses obtained by applying this method show that all the coefficients still have the expected signs and all remain statistically significant. This means that the findings previously presented in the paper are robust to endogeneity issues.

Insert Table 7 about here 


\section{CONCLUSIONS, LIMITATIONS AND FUTURE LINES OF RESEARCH}

The authors have empirically explored the relationship that exists between the information quality of the CSR reporting of the most liquid companies operating in the Spanish Stock Market and their corporate reputation. Based on the legitimacy theory, scholars have traditionally defended the relevance of CSR reporting as a useful tool to generate and manage corporate reputation (de Quevedo et al., 2007; King and Whetten, 2008). In the present study, this argument is explored in depth to defend that not only the quantity of information provided in CSR reporting is useful to generate corporate reputation. In addition to quantity, the authors suggest that information quality is an essential feature of transparency that companies should necessarily manage to improve their corporate reputation through CSR reporting (Toms, 2002; de los Ríos et al., 2012).

More specifically, the legitimacy theory proposes that the institutional pressures faced by companies in the CSR field encourage companies to invest more resources in CSR initiatives and disclose more transparent information in their annual reports (Brammer and Pavelin, 2008; Nikolaeva and Bicho, 2011; Fernández-Feijoo et al., 2014). In this context, both information quantity and quality are important variables that contribute to the improvement of the transparency of CSR reporting (Chauvey et al., 2014) and they are direct consequences of the increased pressures from stakeholders that companies in many industries face nowadays (Brammer and Pavelin, 2008). More specifically, information quality is one of the main goals that internationally accepted CSR standards (e.g., GRI Guidelines) pursue when they develop voluntary reporting frameworks to assist companies in the reporting of their CSR initiatives. The compliance of CSR reporting to one or more of these standards derives into CSR information that is especially relevant, comparable, verifiable, clear and neutral (Chauvey et al., 2014). Therefore, this high quality information creates greater expectations 
among stakeholders; and companies that meet these expectations improve their reputation significantly in a continuous cycle that leads to greater reporting transparency over the years (Bebbington et al., 2014).

The findings of the paper confirm these premises and suggest that companies should necessarily control two axes of information quality in order to improve their corporate reputation. On the one hand, companies should be especially careful about the content of their CSR reporting, which reflects the compliance of CSR reports to the main CSR standards provided by international organizations such as the GRI or the UN. Providing information in such a way that it represents the compliance with these international standards assures that the recipients of information have access to qualitative, quantitative and evaluative information that clearly reflects the activities implemented by the company as well as the results achieved in terms of the contribution of the company to the economic, social and environmental development of the society. This type of information contributes to corporate reputation accordingly. On the other hand, reporting significant information about the CSR management systems applied by the company also has positive impacts on the generation of corporate reputation. This second axis refers to the compliance of CSR reports to the standards of international organizations that relate to the disclosure of details about the programs, plans and management systems that the company designs to assure an effective CSR management.

As for which of the two axis contributes more to the generation of corporate reputation, the findings of this research show that both of them explain a similar amount of the variability of the dependent variable in the regression models. This could be so due to the high correlation between both axes, which indicates that those companies that score high in the content axis also score high in the management systems axis. Similarly, the companies that 
score low in one axis also score low in the other axis. These findings corroborate that the companies that are especially committed to CSR and transparent reporting present high quality information in most of the indicators that the internationally accepted CSR standards suggest as necessary to demonstrate the company's commitment to stakeholders. Thus, the content on economic, social and environmental actions along with the information about the CSR management systems implemented by the company are equally relevant in the development of transparent and high quality CSR reporting and they generate similar results in terms of corporate reputation.

These findings have significant implications for the management of CSR reporting and corporate reputation in companies. First, it is necessary to insist that companies bear an important responsibility for the impact of their operations in the society and the environment. In this sense, it is considered that the companies that do not even communicate the assumption of economic, social and environmental commitments, are in a very primary stage of evolution in the management of their CSR and they are exposed to an increased risk of rights violations and irresponsible practices (CSR Observatory, 2013). Thus, an important implication of this paper is the necessity that companies report on their CSR initiatives, management systems and results in order to embrace their economic, social and environmental duties and be accountable to the society.

In addition to this idea, the findings reported in this paper suggest that the future does not simply imply to generate more CSR activity and disclose an increasing volume of information on CSR. On the contrary, companies should start by being responsible in disclosing the information they already generate under a minimum standard of quality and transparency. Companies should especially care about the quality of the content of their CSR reporting in the sense that corporate reports should not only include large amounts of qualitative and 
evaluative information on the achievements of the company. Companies should also accompany their reporting with sufficient quantitative information concerning the impacts of the CSR initiatives that they have implemented over the year. Additionally, the society expects to know how companies are dealing with their CSR duties and which mechanisms they are implementing to comply with their responsibilities. Thus, the information provided in CSR reporting should also be highly consistent and show the real policies and plans that companies implement to assure high quality CSR management and impacts on the society and environment.

However, the evidence provided in this paper suggests that companies in the lbex35 index are currently not working adequately in terms of the information quality of their CSR reporting. The univariate findings discussed previously in the paper indicate that companies are far from achieving the highest assessment in the measurement tool provided by the CSR Observatory. They are actually way below this mark, especially in the Content axis evaluated by this nonprofit organization. Thus, the third implication derived from this study refers to the necessity that companies in Spain pay more attention to the quality of their reporting in order to equate it to the international standards and benefit from the multiplier effect that the information quality of CSR reporting has on corporate reputation. This finding is in accordance with the situation identified in other countries (e.g., France) where scholars have identified significant increases in the space allocated to CSR reporting, as well as some evidence of increased quality, although the information quality of the reports remains quite low and few companies include negative performance information in their reports (Chauvey et al., 2014).

Finally, this study is not without limitations and future research should consider them to improve the knowledge on the link between CSR reporting and corporate reputation. First, in 
this paper the authors have relied on the CSR Observatory to evaluate the information quality of the CSR reporting of the companies in the sample. This organization only evaluates the information reported in CSR and annual reports. Future research should develop new ways of evaluating CSR reporting that also include online information or any other documents regularly published by companies. Second, although the sample size in the study is similar to the sample size used by previous scholars along the same research line (de los Ríos et al., 2012), it still represents a limitation of the study from the point of view of the generalization of the findings to other research contexts. Specifically, the companies analyzed in this paper are not all the companies operating in the Spanish Stock Market. This being so, it would be necessary for future scholars to use larger samples to determine whether the findings in this paper are also representative of the relationship between CSR reporting and corporate reputation among other companies with different characteristics from the companies included in the Ibex35 index.

\section{REFERENCES}

Aerts, W. and Cormier, D. (2009), "Media legitimacy and corporate environmental communication", Accounting, Organizations and Society, Vol. 34 No. 1, pp. 1-27.

Aguinis, H. and Glavas, A. (2012), "What we know and don't know about corporate social responsibility: A review and research agenda", Journal of Management, Vol. 38 No. 4, pp. 932968.

Bebbington, J.; Larrinaga, C. and Moneva, J.M. (2008), “Corporate social reporting and reputation risk management", Accounting, Auditing \& Accountability Journal, Vol. 21 No. 3, pp. 337-361. 
Brammer, S.J. and Pavelin, S. (2008), "Factors influencing the quality of corporate environmental disclosure", Business Strategy and the Environment, Vol. 17, pp. 120-136.

Carter, S.M. (2006), "The interaction of top management group, stakeholder, and situational factors on certain corporate reputation management activities", Journal of Management Studies, Vol. 43 No. 5, pp. 1145-1176.

Chauvey, J.; Giordano-Spring, S.; Cho, C.H. and Patten, D.M. (2014), "The normativity and legitimacy of CSR disclosure: Evidence from France", Journal of Business Ethics, published online.

Coebergh, H.P.T. (2011), "Voluntary disclosure of corporate strategy: Determinants and outcomes", doctoral thesis, University of Bradford, Bradford (United Kingdom).

Cormier, D. and Magnan, M. (2015), "The economic relevance of environmental disclosure and its impact on corporate legitimacy: An empirical investigation", Business Strategy and the Environment, Vol. 24, pp. 431-450.

CSR Observatory (2013), "Corporate Social Responsibility in the Annual Reports of the IBEX 35 companies", Observatorio de Responsabilidad Social Corporativa, available online. URL: http://observatoriorsc.org/. Accessed on $3^{\text {rd }}$ August 2015.

Deegan, C. (2002), "The legitimising effect of social and environmental disclosures - A theoretical foundation", Accounting, Auditing \& Accountability Journal, Vol. 15 No. 3, pp. 282311.

de la Fuente, J.M. and de Quevedo, E. (2003), “The concept and measurement of corporate reputation: An application to Spanish financial intermediaries", Corporate Reputation Review, Vol. 5 No. 4, pp. 280-301.

de los Ríos, A.; Ruiz, M.; Tirado, P. and Carbonero, M. (2012), "An approach to the relationship between the information about Spanish financial entities' social responsibiltiy 
with respect to customers and their own corporate reputation", Cuadernos de Economía y Dirección de la Empresa, Vol. 15, pp. 130-140.

de Quevedo, E.; de la Fuente, J.M. and Bautista, J. (2007), “Corporate social performance and corporate reputation: Two interwoven perspectives", Corporate Reputation Review, Vol. 10 No. 1 , pp. $60-72$.

Dubbink, W.; Graafland, J. and van Liedekerke, L. (2008), "CSR, transparency and the role of intermediate organizations", Journal of Business Ethics, Vol. 82 No. 2, pp. 391-406.

Fernández-Feijoo, B.; Romero, S. and Ruiz, S. (2014), “Effect of stakeholders' pressure on transparency of sustainability reports within the GRI framework", Journal of Business Ethics, Vol. 122, pp. 53-63.

Fombrun, C.J. and Shanley, M. (1990), "What's in a name? Reputation building and corporate strategy", Academy of Management Journal, Vol. 33 No. 2, pp. 233-258.

Gray, R.; Owen, D. and Adams, C. (1996), Accounting and Accountability: Changes and Challenges in Corporate and Social Reporting, Prentice-Hall, London (United Kingdom).

GRI (2014), “G4 Sustainability Reporting Guidelines. Reporting Principles and Standard Disclosures", Global Reporting Initiative, available online. URL: https://www.globalreporting.org/Pages/default.aspx. Accessed on $3^{\text {rd }}$ August 2015.

Hillman, A.J. and Keim, G.D. (2001), "Shareholder value, stakeholder management and social issues: What's the bottom line?", Strategic Management Journal, Vol. 22, pp. 125-139. Hughes, S.B.; Anderson, A. and Golden, S. (2001), “Corporate environmental disclosures: Are they useful in determining environmental performance?", Journal of Accounting and Public Policy, Vol. 20 No. 3, pp. 217-240. 
King, B.G. and Whetten, D.A. (2008), "Rethinking the relationship between reputation and legitimacy: A social actor conceptualization", Corporate Reputation Review, Vol. 11 No. 3, pp. 192-207.

Lightstone, K. and Driscoll, C. (2008), “Disclosing elements of disclosure: A test of legitimacy theory and company ethics", Canadian Journal of Administrative Sciences, Vol. 25, pp. 7-21.

Lii, Y. and Lee, M. (2012), "Doing right leads to doing well: When the type of CSR and reputation interact to affect consumer evaluations of the firm", Journal of Business Ethics, Vol. 105, pp. 69-81.

Luna, L. and Fernández, J. L. (2010), “Corporate social reporting for different audiences: The case of multinational corporations in Spain", Corporate Social Responsibility and Environmental Management, Vol. 17 No. 5, pp. 272-283.

Michelon, G. (2011), "Sustainability disclosure and reputation: A comparative study", Corporate Reputation Review, Vol. 14 No. 2, pp. 79-96.

Nikolaeva, R. and Bicho, M. (2011), "The role of institutional and reputational factors in the voluntary adoption of corporate social responsibility reporting standards", Journal of the Academy of Marketing Science, Vol. 39, pp. 136-157.

Patten, D.M. (1992), "Intra-industry disclosure in response to the Alaskan oil spill: A note on legitimacy theory", Accounting, Organizations and Society, Vol. 17 No. 5, pp. 471-475.

Pfarrer, M.D.; Pollock, T.G. and Rindova, V.P. (2010), "A tale of two assets: The effects of firm reputation and celebrity on earnings surprises and investors' reactions", Academy of Management Journal, Vol. 53 No. 5, pp. 1131-1152. 
Smith, M. and Taffler, R. (2000), "The chairman's statement: A content analysis of discretionary narrative disclosures", Accounting, Auditing and Accountability Journal, Vol. 13 No. 5, pp. 624-646.

Suchman, M.C. (1995), "Managing legitimacy: Strategic and institutional approaches", Academy of Management Review, Vol. 20, pp. 571-610.

Toms, J.S. (2002), "Firm resources, quality signals and the determinants of corporate environmental reputation: Some UK evidence", British Accounting Review, Vol. 34 No. 3, pp. 257-282.

Unerman, J. (2008), "Strategic reputation risk management and corporate social responsibility reporting", Accounting, Auditing \& Accountability Journal, Vol. 21 No. 3, pp. 362-364.

van Riel, C.B. (2000), Corporate Communication Orchestrated by a Sustainable Corporate Story. The Expressive Organization, Oxford University Press, Oxford (United Kingdom).

Willis, A.C.A. (2003): “The role of the Global Reporting Initiative's Sustainability Reporting Guidelines in the social screening of investments", Journal of Business Ethics, Vol. 43 No. 3, pp. 233-237. 
Table 1. Industry distribution of the sample

\begin{tabular}{lrrrr}
\hline \hline Year & Basic industries & $\begin{array}{r}\text { Consumer goods } \\
\text { and services }\end{array}$ & Finance & Total \\
\hline Companies & 16 & 11 & 8 & $\mathbf{3 5}$ \\
\hline \hline Observations & 130 & 73 & 71 & $\mathbf{2 7 4}$ \\
\hline \hline
\end{tabular}

Table 1 presents the industry distribution of the companies and observations in the sample.

Table 2. Reputation: Dimensions and items

\begin{tabular}{|c|c|c|}
\hline Factor & Items & Expert raters \\
\hline & Financial results & \\
\hline \multirow[t]{2}{*}{ Financial results } & Solvency & Financial analysts \\
\hline & Information quality & \\
\hline \multirow{2}{*}{ Product/Service quality } & Product/Service quality & Consumer \\
\hline & Respect for the rights of customers & associations \\
\hline \multirow{3}{*}{ Management } & Quality of Management & Other opinion \\
\hline & Innovation & leaders \\
\hline & Competitive strategy & (academics) \\
\hline \multirow{5}{*}{ Ethics and corporate responsibility } & Commitment to the community & \multirow{5}{*}{$\begin{array}{l}\text { NGOs and } \\
\text { journalists }\end{array}$} \\
\hline & Social and environmental responsibility & \\
\hline & Information transparency & \\
\hline & Accessibility & \\
\hline & Management of corporate communication & \\
\hline Internal reputation & Working quality & Unions \\
\hline \multirow{3}{*}{ Digital communication } & Management of digital communication & \multirow{3}{*}{$\begin{array}{l}\text { People linked to } \\
\text { the area of digital } \\
\text { communication }\end{array}$} \\
\hline & Ethics (honesty and transparency) & \\
\hline & Innovation in digital communication & \\
\hline
\end{tabular}

Table 2 presents the factors and items that are rated by experts to build the annual MercoEmpresas ranking of the top 100 companies with the highest reputation in Spain (Spanish Corporate Reputation Monitor, Merco). 
Table 3. Information quality: Dimensions and items

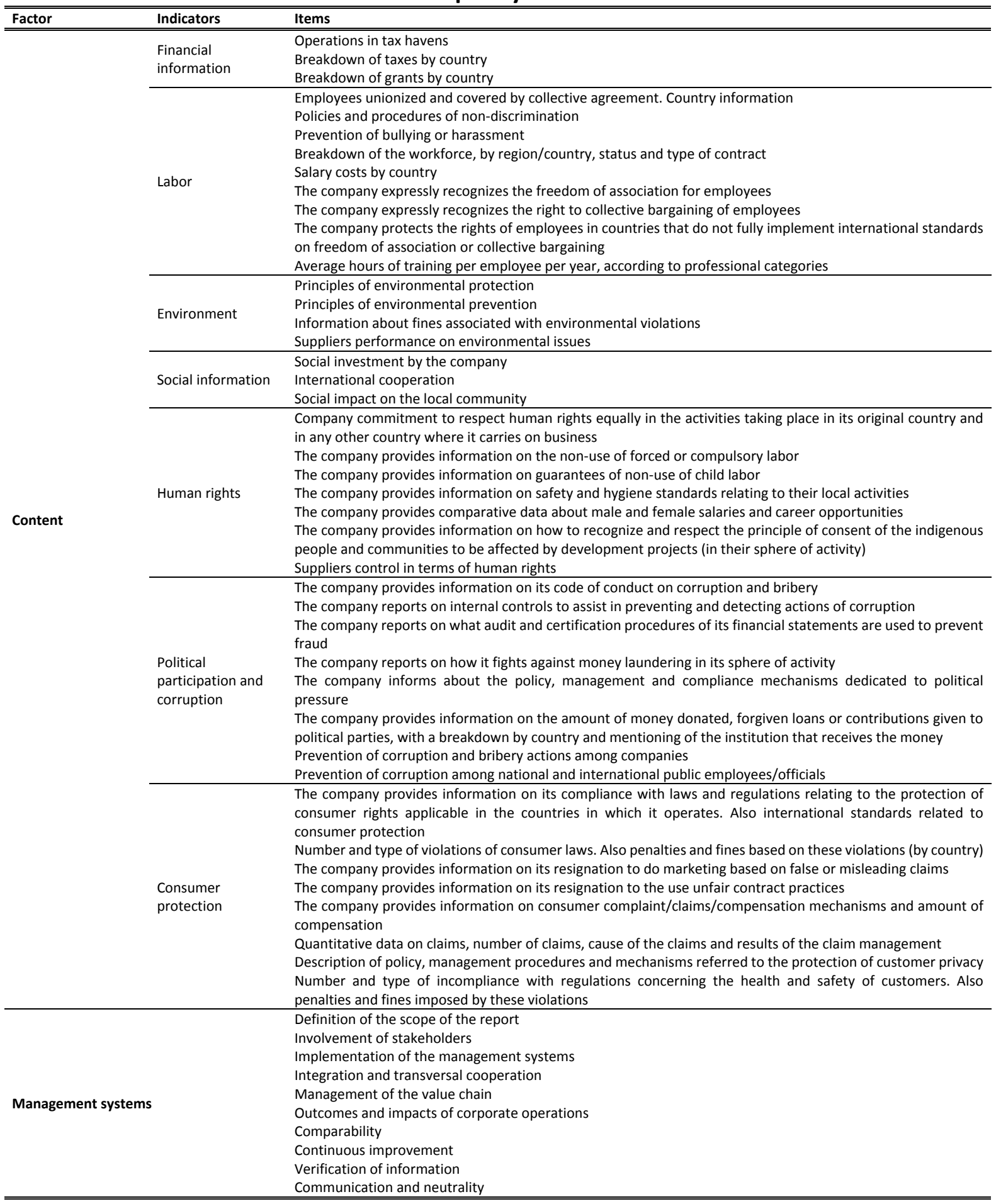

Table 3 presents the factors and items that are rated by experts of the Spanish CSR Observatory to evaluate the (global) information quality of the CSR reporting of the 35 companies that are explored in the research. 
Table 4. Descriptive statistics

\begin{tabular}{lrrrrrr}
\hline \hline Variable & Companies & Observations & Mean & Std. Dev. & Min & Max \\
\hline REPUT & 35 & 274 & 8.49 & 0.44 & 7.10 & 9.21 \\
IQCSRR & 35 & 274 & 1.33 & 0.43 & 0.00 & 2.18 \\
CONT & 35 & 274 & 1.02 & 0.48 & 0.00 & 2.05 \\
MANASYS & 35 & 274 & 1.36 & 0.56 & 0.00 & 2.69 \\
SIZE & 35 & 274 & 17.11 & 1.57 & 12.46 & 20.96 \\
ROE & 35 & 274 & 0.14 & 0.24 & -1.66 & 0.79 \\
AGE & 35 & 274 & 3.95 & 0.70 & 1.79 & 5.06 \\
\hline
\end{tabular}

Table 4 presents the descriptive statistics for all the variables in the study. In this table, the mean, standard deviation, minimum and maximum values of each variable are presented.

REPUT = corporate reputation of the company; IQCSRR = global information quality of the CSR reporting; CONT = information quality of the CSR reporting on the 'content' axis; MANASYS = information quality of the CSR reporting on the 'management systems' axis; SIZE = total assets of the company; ROE = return on equity (financial performance); $A G E=$ years since establishment.

Table 5. Correlation matrix

\begin{tabular}{lrrrrrr}
\hline \hline & IQCSRR & \multicolumn{1}{c}{ CONT } & MANASYS & SIZE & ROE & AGE \\
\hline \hline IQCSRR & 1 & & & & & \\
CONT & 0.91 & 1 & & & & \\
MANASYS & 0.95 & 0.89 & 1 & & & \\
SIZE & 0.30 & 0.41 & 0.25 & 1 & & \\
ROE & 0.13 & 0.04 & 0.09 & 0.00 & 1 & \\
AGE & 0.09 & 0.18 & 0.10 & 0.49 & -0.09 & 1 \\
\hline \hline
\end{tabular}

Table 5 presents the correlations among all the variables in the study.

IQCSRR = global information quality of the CSR reporting; CONT = information quality of the CSR reporting on the 'content' axis; MANASYS = information quality of the CSR reporting on the 'management systems' axis; SIZE = total assets of the company; ROE = return on equity (financial performance); $\mathrm{AGE}=$ years since establishment. 
Table 6. Findings of the panel data analyses (Fixed-Effects estimator)

\begin{tabular}{|c|c|c|c|c|c|c|}
\hline \multirow[b]{2}{*}{ IQCSRR } & \multicolumn{2}{|c|}{ Model 1} & \multicolumn{2}{|c|}{ Model 1a } & \multicolumn{2}{|c|}{ Model 1b } \\
\hline & $\begin{array}{l}0.256 \\
(3.00)\end{array}$ & $* * *$ & & & & \\
\hline CONT & & & $\begin{array}{l}0.246 \\
(2.85)\end{array}$ & $* * *$ & & \\
\hline MANASYS & & & & & $\begin{array}{l}0.192 \\
(2.59)\end{array}$ & $* *$ \\
\hline SIZE & $\begin{array}{l}0.112 \\
(2.04)\end{array}$ & $* *$ & $\begin{array}{l}0.122 \\
(2.27)\end{array}$ & $* *$ & $\begin{array}{l}0.115 \\
(1.97)\end{array}$ & \\
\hline ROE & $\begin{array}{l}-0.039 \\
(-0.99)\end{array}$ & & $\begin{array}{l}-0.040 \\
(-0.97)\end{array}$ & & $\begin{array}{l}-0.044 \\
(-1.11)\end{array}$ & \\
\hline AGE & $\begin{array}{l}-0.388 \\
(-1.72)\end{array}$ & $*$ & $\begin{array}{l}-0.406 \\
(-1.71)\end{array}$ & $*$ & $\begin{array}{l}-0.401 \\
(-1.70)\end{array}$ & $*$ \\
\hline CONSTANT & $\begin{array}{l}7.792 \\
(6.80)\end{array}$ & $* * *$ & $\begin{array}{l}6.311 \\
(7.03)\end{array}$ & $* * *$ & $\begin{array}{l}7.872 \\
(6.23)\end{array}$ & $* * *$ \\
\hline $\begin{array}{l}\text { SECTOR } \\
\text { YEAR }\end{array}$ & $\begin{array}{l}3.34 \\
9.29\end{array}$ & $\begin{array}{l}* * * \\
* * *\end{array}$ & $\begin{array}{l}2.99 \\
8.79\end{array}$ & $\begin{array}{l}* \\
* * *\end{array}$ & $\begin{array}{l}3.83 \\
9.20\end{array}$ & $\begin{array}{l}* \\
* * *\end{array}$ \\
\hline $\begin{array}{l}\text { Hausman test } \\
\text { F test }\end{array}$ & $\begin{array}{l}28.13 \\
19.59 \\
\end{array}$ & $\begin{array}{l}* * \\
* * * \\
\end{array}$ & $\begin{array}{l}30.54 \\
20.08 \\
\end{array}$ & $\begin{array}{l}* * \\
* * * \\
\end{array}$ & $\begin{array}{l}39.77 \\
20.89 \\
\end{array}$ & $\begin{array}{l}* * * \\
* * * \\
\end{array}$ \\
\hline $\mathbf{R}^{2}$ & 0.6018 & & 0.599 & & 0.598 & \\
\hline
\end{tabular}

Table 6 presents the results of the three regression analyses that test the Models (1), (1a) and (1b) using the fixed-effect model through the robust estimator that uses the Huber/White/Sandwich correction.

IQCSRR = global information quality of the CSR reporting. CONT = information quality of the CSR reporting on the 'content' axis. MANASYS = information quality of the CSR reporting on the 'management systems' axis. SIZE = total assets of the company. $\mathrm{ROE}=$ return on equity (financial performance). $\mathrm{AGE}=$ years since establishment. SECTOR $=$ Wald's test of the joint significance of the sector's dummy variables. YEAR = Wald's test of the joint significance of the year's dummy variables, distributed as a chi-square under the null hypothesis of lack of relationship.

- Hausman test is the implementation of Hausman's specification test, under the null hypothesis that there should be no systematic difference between the fixed and random effects estimators.

- $F$ test is presented under the null hypothesis that the individual fixed effects are equal to zero.

$* * *$ indicates a level of significance of $0.01, * *$ indicates a level of significance of 0.05 . T-statistic in brackets. 
Table 7. Findings of the panel data analyses (Instrumental variables fixed-effects estimator)

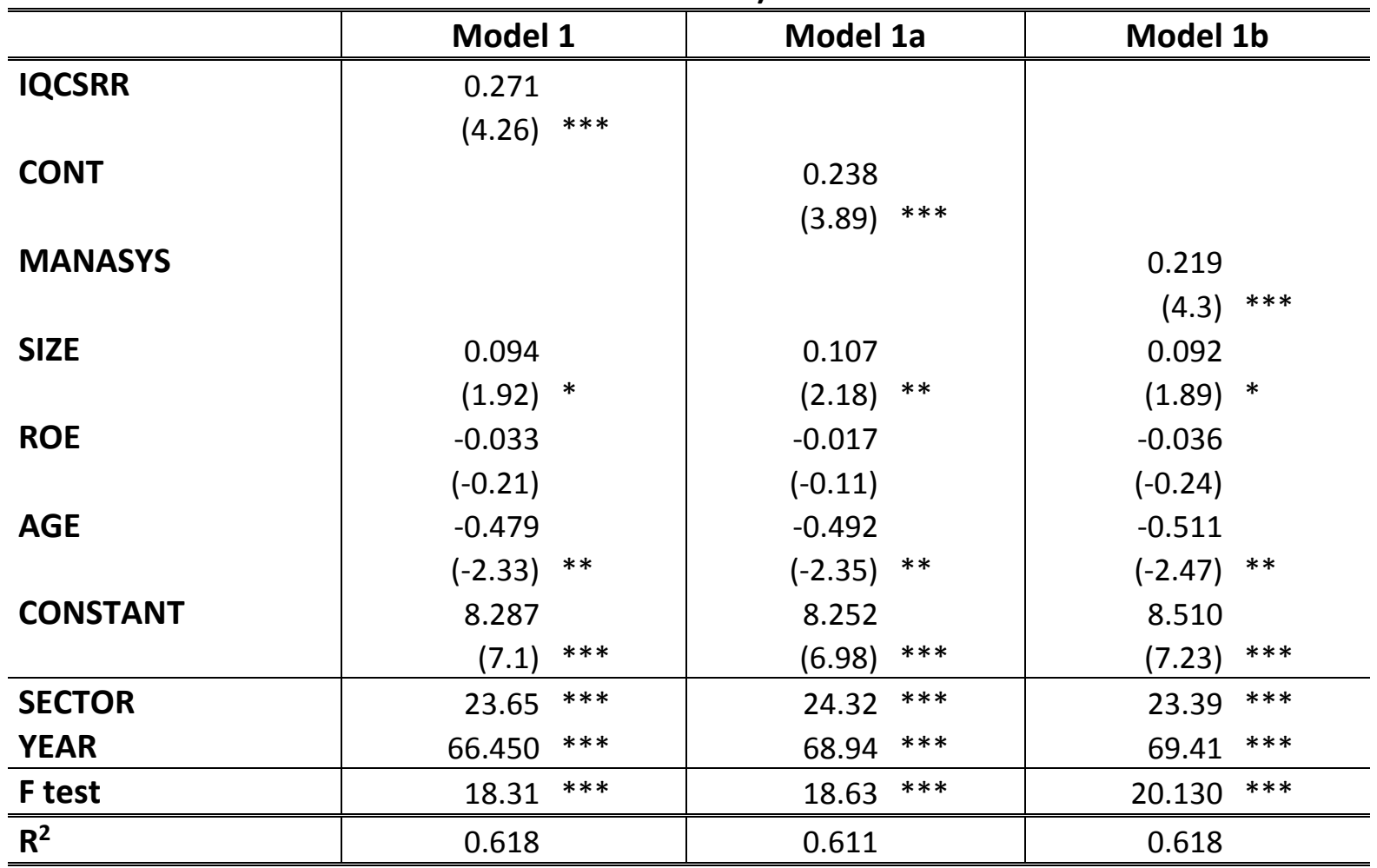

Table 7 presents the results of the three regression analyses that test the Models (1), (1a) and (1b) using two-stage leastsquares within estimator with instrumental variables.

IQCSRR = global information quality of the CSR reporting. CONT = information quality of the CSR reporting on the 'content' axis. MANASYS = information quality of the CSR reporting on the 'management systems' axis. SIZE = total assets of the company. $R O E=$ return on equity (financial performance). $A G E=$ years since establishment. SECTOR $=$ Wald's test of the joint significance of the sector's dummy variables. YEAR = Wald's test of the joint significance of the year's dummy variables, distributed as a chi-square under the null hypothesis of lack of relationship.

- $F$ test is presented under the null hypothesis that the individual fixed effects are equal to zero.

$* * *$ indicates a level of significance of $0.01, * *$ indicates a level of significance of 0.05 . T-statistic in brackets. 
Figure 1. Conceptual framework of the legitimacy theory

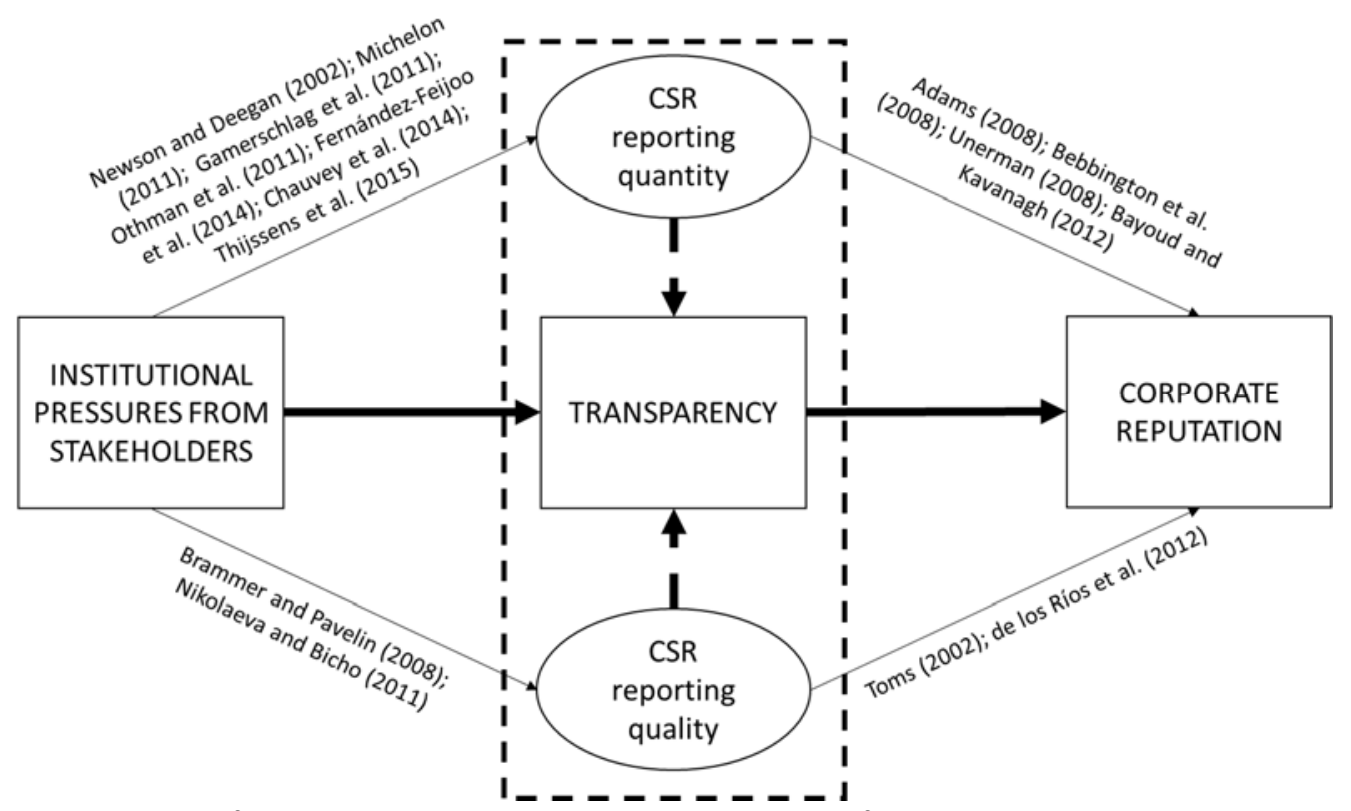

Figure 1 presents some of the previous literature that has empirically confirmed the relationships among the concepts explored by the legitimacy theory.

Figure 2. The information quality of CSR reporting between 2004 and 2013

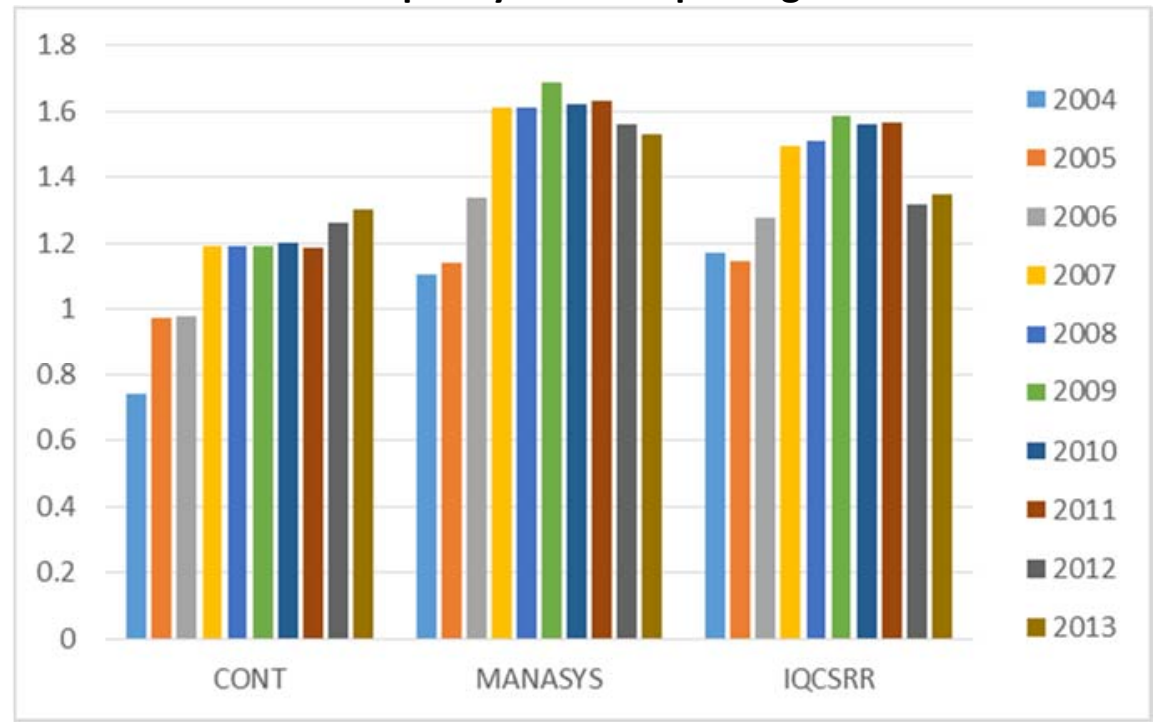

Figure 2 presents a summary of the (global) information quality of the CSR reporting of the 35 companies that are explored in the research as rated by the Spanish CSR Observatory in 2013. This rating uses a scale of $0-4$, where $0=$ nonexistent quality; $0.1-1$ = anecdotal quality; 1.01-2 = poor quality; $2.01-3$ = incomplete quality; $3.01-3.99=$ complete quality; $4=$ comprehensive quality. 